\title{
Gingival peripheral odontoma in a child: Case report of an uncommon lesion
}

\author{
Ji Hyun Kwon ${ }^{1}$, Young Ah Cho ${ }^{2}$ Hong Keun Hyun ${ }^{1}$, Teo Jeon Shin ${ }^{1}$, Young Jae Kim ${ }^{1 *}$ \\ ${ }^{1}$ Department of Pediatric Dentistry, School of Dentistry, Seoul National University, Seoul, South Korea \\ ${ }^{2}$ Department of Oral Pathology, School of Dentistry, Seoul National University, Seoul, South Korea \\ Email: jihyun.peony@gmail.com
}

Received 2 February 2013; revised 6 March 2013; accepted 15 March 2013

\begin{abstract}
Odontomas are defined as hamartomas of odontogenic origin. They are composed of all dental tissues are represented, occurring in a more or less disorderly pattern. Intraosseous (central) odontomas are the odontogenic tumors of greatest incidence. Otherwise, odontomas arising in the extraosseous soft tissue, also known as peripheral odontoma, are extremely uncommon. This article presents a case of peripheral odontoma in a child referred to SNUDH for treatment. A 2-year-old girl was referred to The SNUDH regarding an asymptomatic nodule on the left maxillary buccal gingiva. Clinical examination revealed a 7 $\mathrm{mm} \times 6 \mathrm{~mm} \times 3 \mathrm{~mm}$, sessile mucosal lesion on the buccal gingival between \#62 and \#63. The lesion was firm on palpation and covered with an intact nonulcerated mucosa. There was no other mucosal pathology. Under $\mathrm{N}_{2} \mathrm{O}-\mathrm{O}_{2}$ inhalation sedation, an excisional biopsy of the lesion was performed. The diagnosis was peripheral odontoma. Summary: Odontoma in an extraosseous location represents a challenge for diagnosis. This article reports a case of peripheral odontoma and its clinical presentation, histological evaluation and treatment. A 2-year-old girl reported a firm asymptomatic nodule on left maxillary buccal gingival. The procedures for diagnosis included intraoral examination, excisional biopsy and histological analysis. The diagnosis was peripheral odontoma. Peripheral odontoma is rare and the differential diagnosis with other gingival masses is rather difficult and must include inflammatory and reactive processes. The definitive diagnosis is based on microscopic features.
\end{abstract}

Keywords: Peripheral Odontoma; Soft Tissue Odontoma

\section{INTRODUCTION}

Odontomas are considered hamartomatous malforma-

\footnotetext{
"Corresponding author.
}

tions of odontogenic origin in which all dental tissues are represented [1]. They occurs in a more or less disorderly pattern. These lesions are usually diagnosed at teenages and have no predilection for sex [1]. The reason of the odontoma is unknown [2]. However, it is thought to be hereditary or due to a disturbance in tooth development triggered by trauma or infection [2].

The intraosseous or central odontomas represent the odontogenic tumors of greatest incidence [1]. They are represented $51 \%$ of all odontogenic tumors [3]. Otherwise, odontomas arising in the extraosseous soft tissue, also known as peripheral odontoma or soft tissue odontoma, are extremely uncommon [1]. They are defined as tumors with the histological characteristics of intraosseous odontoma but occurring only in the soft tissue [3]. Only a few cases of peripheral odontoma have been reported to date [3]. This article presents a case of peripheral odontoma arising in the gingival in a child referred to SNUDH for treatment.

Aim: The aim of this paper was to describe the case of a peripheral odontoma located on the left maxillary buccal gingiva of a 2-year-old girl.

\section{CASE REPORT}

A 2-year-old girl was referred to the SNUDH regarding an asymptomatic nodule on left maxillary buccal gingiva. She has no premedical history and predental history. Clinical examination revealed a $7 \mathrm{~mm} \times 6 \mathrm{~mm} \times 3 \mathrm{~mm}$, sessile mucosal lesion on the buccal gingival between \#62 and \#63 (Figure 1). The lesion was firm on palpation and covered with an intact non-ulcerated mucosa. There was no other mucosal pathology. Radiographic examination revealed nothing other than some space of the area (Figure 2). The tentative diagnosis was fibrous gingival hyperplasia.

Under $\mathrm{N}_{2} \mathrm{O}-\mathrm{O}_{2}$ inhalation sedation, an excisional biopsy of the lesion was performed. No bone involvement was observed during the surgery (Figure 3 ). The specimen was immediately placed in 10\% neutral buffered formalin, processed in the usual manner and submitted 

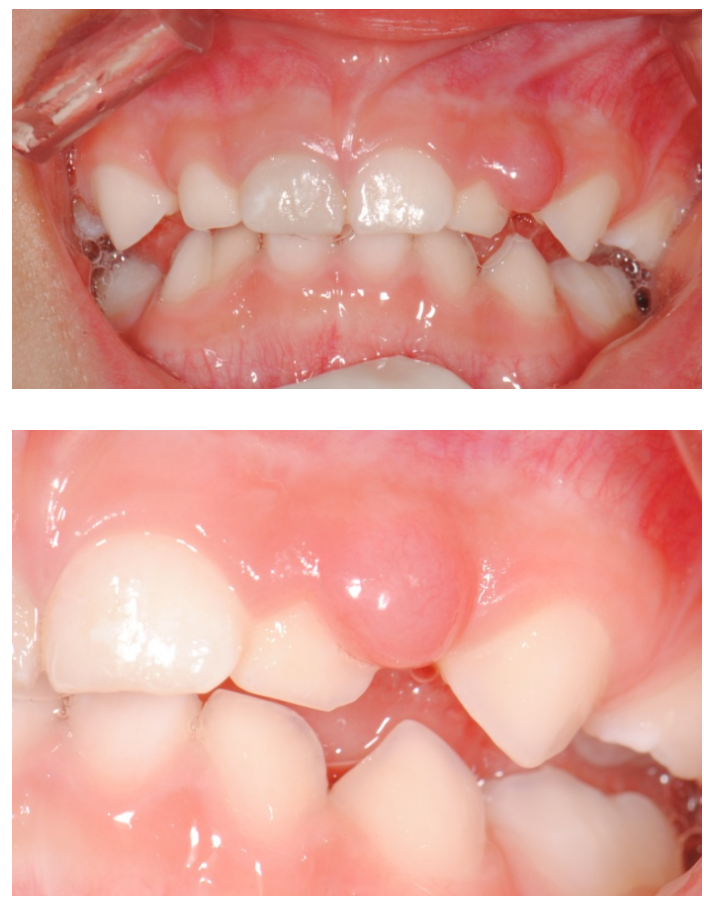

Figure 1. Clinical presentation of the lesion.

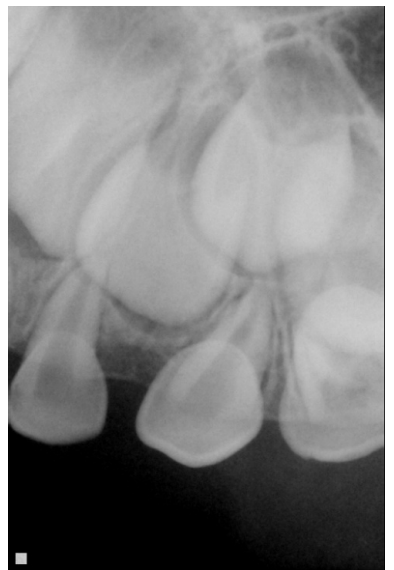

(a)

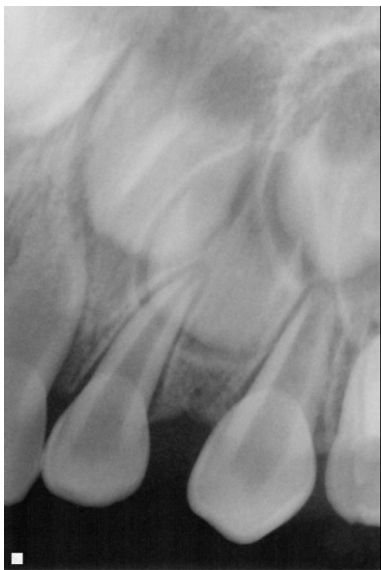

(b)
Figure 2. Periapical radiograph of the lesion (a) Pre-operation; (b) 2 years post-operation.

for histopathological analysis.

On microscopic examination (Figure 4), loose fibrous capsule was surrounding a tooth germ-like structure in dense collagenous gingival tissue. The relationship between dental papilla and enamel organ was reminiscent of a developing tooth. However, the inner and outer enamel epithelia did not form certain tooth morphology. Ghost cells were partially observed within the enamel organ around juxtaepithelial dentinoid material. The definitive diagnosis was peripheral odontoma.

The two-week postoperative follow-up showed that the area had already healed. Two years later, there is still no clinical sign of recurrence (Figures 2 and 5).

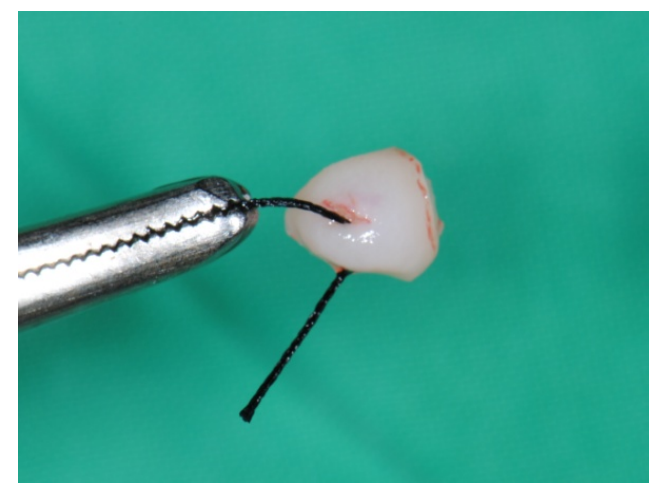

(a)

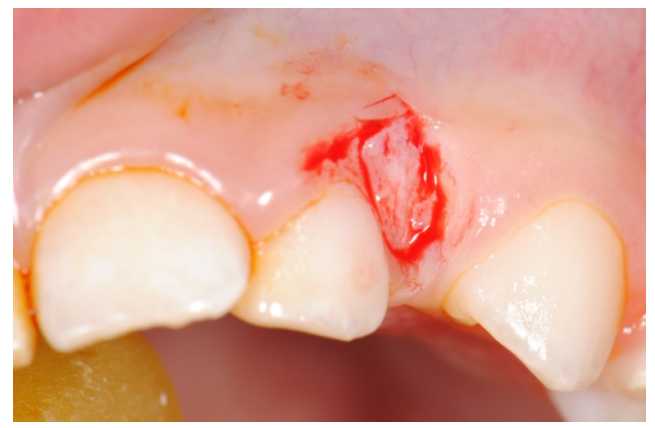

(b)

Figure 3. (a) Surgical specimen exhiting a soft tissue lesion; (b) Excised.

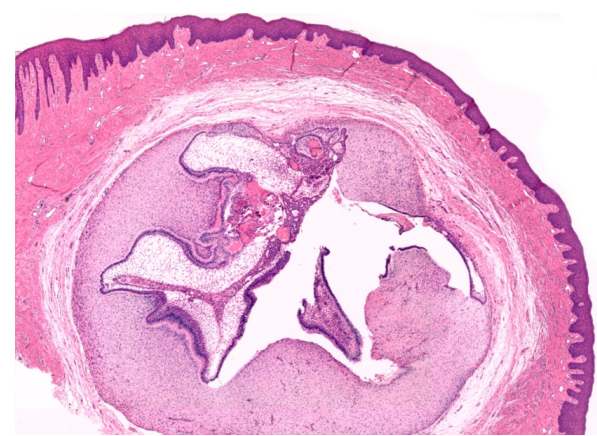

(a)

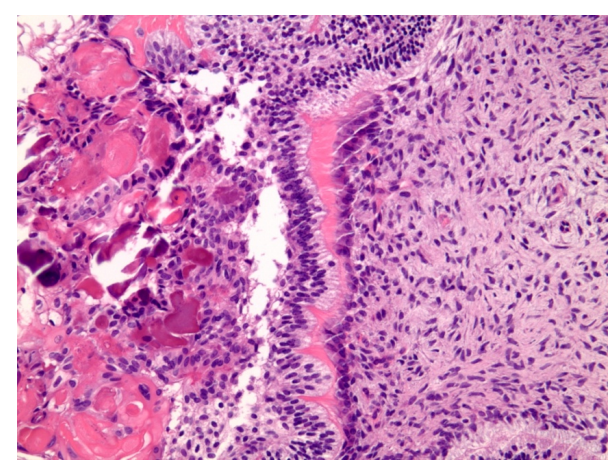

(b)

Figure 4. Photomicrograph of the lesion (a) Developing microdont within gingival (haematoxylin and eosin $\times 40$ ); (b) Ghost cells in enamel organ $(H \& E \times 200)$. 


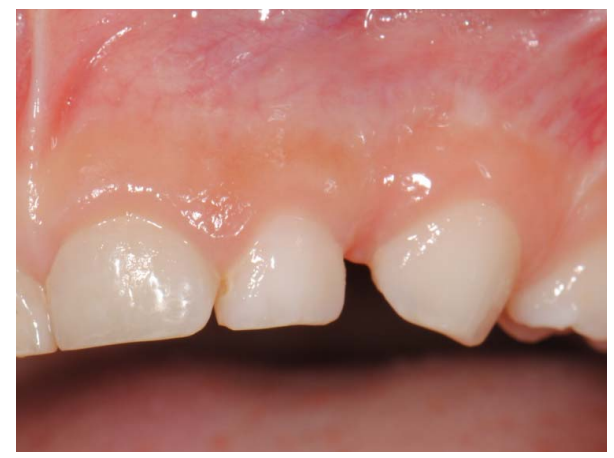

Figure 5. Clinical representation of the region 2 years post-operatively.

\section{DISCUSSION}

On very rare occasions, odontomas may occur in extraosseous location [4]. It is likely that so-called soft-tissue mesiodens is an erupted form of pheripheral odontoma (PO) [4]. PO represents a challenge for diagnosis. PO is rare and the differential diagnosis with other gingival masses is rather difficult and must include inflammatory (e.g., periodontal abscess) and reactive processes (e.g., pyogenic granuloma, peripheral ossifying fibroma, peripheral giant cell granuloma) [4]. In previously reported cases, the most prevalent site was incisor/canine area of the maxilla [1,5]. Especially, palatal PO has been recognized congenital epulis of the newborn. A variety of terms such as irregular eruption, ectopic tooth, ectopic soft-tissue mesiodens, ectopic odontoma and extra-osseous tooth germ can be described [6]. The radiographic features of this lesion can be different. Radiopacity depends on the extent of calcification. In the first stage, it appears radiolucent because of the lack of calcification of dental tissue components [2]. In the intermediate stage, it is partially calcified [2]. The third stage shows classical radiopacity [2]. Therefore, in its early stage, without calcification, it will appear radiolucent and may be mistaken for other entities, such as cyst, central giant cell lesion of bone, or odontogenic tumor. Microscopical analysis of PO exhibited developing tooth germs composed of ameloblasts, enamel matrix, odontoblastic layer, dentin and dental papilla [6]. Although varying degree of differentiation could be seem, tooth germs were invariably surrounded by dense fibrous connective tissue containing islands of odontogenic epithelium and superficially covered by normal stratified squamous epithelium [6]. Different morphological features were found in the previously reported cases of PO. These morphological features seem to depend on the developmental stage of each tooth germ at discovery [6]. These cases show that various types of lesion form part of the clinicopathological spectrum of PO. Due to s lack of consensus for clinical diagnosis of PO, overtreatment could be done. The definitive diagnosis is based on microscopic features. Since these lesions are considered potential, surgical removal should be conservative with no real expectation of recurrence [1]. PO is rare and has been recognized under different names [6]. Most significantly, it is important to keep in mind its clinical and histological characteristics in order to establish the proper diagnosis avoiding confusion other lesions described above, and consequently to avoid overtreatment [6].

\section{REFERENCES}

[1] De Fátima Bernardes, V., de Miranda Cota, L.O., de Oliveira Costa, F., Mesquita, R.A., Gomez, R.S. and Aguiar, M.C.F. (2008) Gingival peripheral odontoma in a child: Case report of an uncommon lesion. Brazilian Journal Oral Sciences, 7, 1624-1626.

[2] Giunta, J.L. and Kaplan, M.A. (1990) Peripheral, soft tissue odontomas: Two case reports. Oral Surgery, Oral Medicine, Oral Pathology, 69, 406-411. doi:10.1016/0030-4220(90)90312-G

[3] Junquera, L., de Vicente, J.C., Roig, P., Olay, S. and Rodríguez-Recio, O. (2005) Odontoma intraóseo erupcionado: Una infrecuente patología Intraosseus odontoma erupted into the oral cavity: An unusual pathology. $\mathrm{Pa}$ thology, 10, 248-251.

[4] Ide, F., Obara, K., Mishima, K., Saito, I., Horie, N., Shimoyama, T., et al. (2005) Peripheral odontogenic tumor: A clinicopathologic study of 30 cases. General features and hamartomatous lesions. Journal of Oral Pathology \& Medicine, 34, 552-557.

[5] Ide, F., Mishima, K., Saito, I. and Kusama, K. (2008) Rare peripheral odontogenic tumors: Report of 5 cases and comprehensive review of the literature. Oral Surgery, Oral Medicine, Oral Pathology, Oral Radiology, and Endodontology, 106, e22-e28. doi:10.1016/j.tripleo.2008.05.064

[6] Silva, A., Carlos-Bregni, R., Vargas, P., de Almeida, O. and Lopes, M. (2009) Peripheral developing odontoma in newborn. Report of two cases and literature review. Medicina Oral Patologia Oral y Cirugia Bucal, 14, e612e615. doi:10.4317/medoral.14.e612 